\title{
Skeletal muscle uncoupling protein 3 (UCP3): mitochondrial uncoupling protein in search of a function
}

Citation for published version (APA):

Schrauwen, P. (2002). Skeletal muscle uncoupling protein 3 (UCP3): mitochondrial uncoupling protein in search of a function. Current Opinion in Clinical Nutrition and Metabolic Care, 5(3), 265-270. https://doi.org/10.1097/00075197-200205000-00005

Document status and date:

Published: 01/01/2002

DOI:

10.1097/00075197-200205000-00005

Document Version:

Publisher's PDF, also known as Version of record

\section{Document license:}

Taverne

Please check the document version of this publication:

- A submitted manuscript is the version of the article upon submission and before peer-review. There can be important differences between the submitted version and the official published version of record.

People interested in the research are advised to contact the author for the final version of the publication, or visit the DOI to the publisher's website.

- The final author version and the galley proof are versions of the publication after peer review.

- The final published version features the final layout of the paper including the volume, issue and page numbers.

Link to publication

\footnotetext{
General rights rights.

- You may freely distribute the URL identifying the publication in the public portal. please follow below link for the End User Agreement:

www.umlib.nl/taverne-license

Take down policy

If you believe that this document breaches copyright please contact us at:

repository@maastrichtuniversity.nl

providing details and we will investigate your claim.
}

Copyright and moral rights for the publications made accessible in the public portal are retained by the authors and/or other copyright owners and it is a condition of accessing publications that users recognise and abide by the legal requirements associated with these

- Users may download and print one copy of any publication from the public portal for the purpose of private study or research.

- You may not further distribute the material or use it for any profit-making activity or commercial gain

If the publication is distributed under the terms of Article $25 \mathrm{fa}$ of the Dutch Copyright Act, indicated by the "Taverne" license above, 


\section{Skeletal muscle uncoupling protein 3 (UCP3): mitochondrial uncoupling protein in search of a function Patrick Schrauwen}

The uncoupling protein 1 homologue, uncoupling protein 3 , is able to uncouple adenosine triphosphate production from mitochondrial respiration, thereby dissipating energy as heat and affecting the efficiency of energy metabolism. Uncoupling protein 3 is expressed predominantly in skeletal muscle, and has been associated with whole-body energy metabolism. However, on the basis of present evidence it has been concluded that the primary function of uncoupling protein 3 is not in the regulation of energy expenditure. For example, fasting, an energy expenditure attenuating condition, upregulates uncoupling protein 3 expression, and uncoupling protein 3 knockout mice have a normal metabolic rate. The exact function of uncoupling protein 3 remains to be elucidated, but at present putative roles for uncoupling protein 3 include involvement in the regulation of the production of reactive oxygen species, mitochondrial fatty acid transport and the regulation of glucose metabolism in skeletal muscle. Because all these putative functions assume that uncoupling protein 3 affects mitochondrial coupling, a secondary effect of the function of uncoupling protein 3 might still be that it influences (but not regulates) energy metabolism, consistent with observations in linkage and association studies. Therefore, uncoupling protein 3 remains an interesting target for pharmacological upregulation in the treatment of obesity and diabetes. Curr Opin Clin Nutr Metab

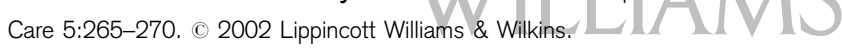

Nutrition and Toxicology Research Institute Maastricht (NUTRIM), Department of Human Biology, Maastricht University, the Netherlands

Correspondence to Dr P. Schrauwen, Department of Human Biology, Maastricht University, PO Box 616, 6200 MD Maastricht, the Netherlands Tel: +31 43 3881639; fax: +31 43 3670976; e-mail: p.schrauwen@hb.unimaas.nl

Current Opinion in Clinical Nutrition and Metabolic Care 2002, 5:265-270

\section{Abbreviations}

ADP adenosine diphosphate

AMP adenosine monophosphate

AMPK adenosine monophosphate-activated protein kinase

ATP adenosine triphosphate

NMR nuclear magnetic resonance

ROS reactive oxygen species

TCA tricarboxylic acid

UCP 1-3 uncoupling proteins 1-3

(C) 2002 Lippincott Williams \& Wilkins 1363-1950

\section{Introduction}

In living cells, the mitochondrial machinery is responsible for the major part of energy production in the form of adenosine triphosphate (ATP). The metabolism of substrates such as fat, carbohydrate and proteins results in the production of reducing equivalents of nicotinamide adenine dinucleotide and flavine adenine dinucleotide 2, which can be oxidized to nicotinamide adenine dinucleotide, flavine adenine dinucleotide and hydrogen in a process called electron transfer or respiratory chain. According to the chemiosmotic hypothesis of Mitchell [1], the net transport of protons to the cytosolic side of the inner mitochondrial membrane generates a proton gradient across the mitochondrial membrane. When this proton gradient is high enough, protons flow back over the inner mitochondrial membrane through a so-called $\mathrm{F}_{0} \mathrm{~F}_{1}$-complex and the energy thus generated is used by ATPase to transform adenosine diphosphate (ADP) into ATP. In this way, substrate oxidation is coupled to the formation of ATP. However, the coupling between substrate oxidation and ATP formation is not $100 \%$ efficient; part of the generated proton gradient is lowered by proton leaks, thereby dissipating energy as heat. It has been suggested that the contribution of proton leaks to the resting metabolic rate can be as large as $20-50 \%$ [2]. In the 1960 s it was shown that proton leaks were the explanation for the increase in thermogenic activity of brown adipose tissue of rodents in response to cold and overfeeding. This feature of brown adipose tissue has led to the search for and identification of a protein responsible for this proton leak. In 1978, it was demonstrated that a 32000 $\mathrm{M}_{\mathrm{r}}$ mitochondrial membrane protein, then called 'uncoupling protein' or 'thermogenin', and later renamed 'UCP1', was responsible for the thermogenic activity of brown adipose tissue [3]. UCP1 could either transport protons into the mitochondrial matrix [4], or transport non-esterified fatty acid anions out of the matrix (in a process called fatty acid cycling) [5], in both ways lowering the proton gradient across the inner mitochondrial membrane. As mitochondria from skeletal muscle, which do not express UCP1, are also characterized by proton leaks, the search for other uncoupling proteins has continued and has resulted in the discovery of two novel uncoupling proteins, UCP2 [6] and UCP3 [7]. In contrast to UCP2, which is ubiquitously expressed in virtually all tissues, UCP3 is restricted to skeletal muscle [7], and is therefore thought to be of importance in skeletal muscle energy metabolism. 


\section{Is UCP3 able to uncouple mitochondria?}

When expressed in yeast, UCP3 has indeed been shown to lower the proton gradient across the inner mitochondrial membrane [8]. Furthermore, mitochondria isolated from mice lacking UCP3 showed a decreased state 4 respiration (equal to the rate of oxygen consumption after all ADP in the mitochondria has been phosphorylated to form ATP), indicating improved coupling [9・•], whereas mitochondria isolated from mice overexpressing UCP3 showed an increased state 4 respiration [10 • ]. Using ${ }^{31} \mathrm{P}$ nuclear magnetic resonance (NMR), Cline et al. $\left[11^{\bullet}\right.$ ] provided evidence for the in-vivo uncoupling activity of UCP3; mice lacking UCP3 showed an increased ratio of the rate of ATP synthesis to tricarboxylic acid (TCA) cycle flux, indicating a two to fourfold higher coupling of oxidative phosphorylation. The mechanism by which UCP3 uncouples mitochondria is, however, still under debate. It has been proposed that UCP3 either transports protons into the mitochondrial matrix [4], or that the proton gradient is lowered by the cycling of fatty acids in the inner mitochondrial membrane, with a role for UCP3 in transporting nonesterified fatty acid anions out of the matrix [5]. Whatever the mechanism, based on the uncoupling activity of UCP3, it would be expected that this mitochondrial protein could play an important role in energy metabolism and body weight regulation.

\section{Is UCP3 involved in energy expenditure and body weight regulation?}

The first evidence of a relationship between UCP3 and energy metabolism has come from genetic studies. The UCP3 gene is located on chromosomal position 11q13, and markers in the vicinity of this location are very strongly linked to resting energy expenditure [12]. Several polymorphisms in the UCP3 gene have been used to examine the association between UCP3 and energy metabolism or obesity. Although many studies report an association between UCP3 and energy expenditure, data on the association between UCP3 and measures of obesity are less consistent (for reviews see Dalgaard and Pedersen [13] and Ricquier and Bouillaud $\left[14^{\bullet \bullet}\right]$ ).

Another approach to determine whether UCP3 is functionally related to energy metabolism and body weight regulation is to measure UCP3 messenger RNA expression or protein content, and directly relate it to measured energy expenditure. Using this approach we found, in Pima Indians [15], that the mRNA expression of UCP3 was positively correlated with the sleeping metabolic rate (which accounts for approximately $60 \%$ of total energy expenditure in humans). Furthermore, two conditions characterized by a reduced resting metabolic rate or improved energy efficiency, weight reduction and endurance training, are accompanied by decreased levels of UCP3 in humans $\left[16,7^{\bullet}\right]$. During cold exposure, extra heat is produced to maintain the body temperature. In accordance with a role for UCP3 in energy metabolism, acute cold exposure in mice resulted in a threefold increase in UCP3 protein content, accompanied by a pronounced lowering of mitochondrial membrane potential [18]. Cancer cachexia is characterized by weight loss, probably as a result of increased energy expenditure. Consistent with a role for UCP3 in energy metabolism, it was found that in rodents, UCP3 was upregulated in the cachexic state [19]. Recent data also point in the direction of a role for UCP3 in thyroid hormone (triiodothyronine)induced thermogenesis [20 $0^{\bullet}$. In hypothyroid rats, the skeletal muscle UCP3 protein content and resting metabolic rate were measured for $144 \mathrm{~h}$ after triiodothyronine injection. The resting metabolic rate and UCP3 protein content showed a similar pattern, both peaking $65 \mathrm{~h}$ after triiodothyronine injection. The measurement of mitochondrial coupling indicated that mitochondria indeed showed increased uncoupling activity when the UCP3 protein content was high. Using ${ }^{31} \mathrm{P}$ NMR, Lebon et al. $\left[21^{\circ}\right]$ found that the TCA cycle flux increased $70 \%$ after triiodothyronine treatment, whereas ATP synthesis was unchanged, indicating increased mitochondrial uncoupling. Although not measured, it is tempting to suggest that increased UCP3 content was responsible for the increased mitochondrial uncoupling. Finally, mice overexpressing UCP3 are hyperphagic, but weigh less than their wild-type littermates, indicating that overexpressing UCP3 increased the metabolic rate [10॰日]. Together, such studies indicated that UCP3 might be able to affect energy metabolism.

However, whether the primary physiological function of UCP3 is the regulation of energy expenditure is under debate! In contrast to what would have been expected, UCP3 knockout mice were found to have normal energy expenditure and body weight, even though their mitochondria showed improved coupling $\left[9^{\bullet \bullet}, 22^{\bullet \bullet}\right]$. Further contrasting data regarding a primary role of UCP3 in energy metabolism came from the findings that fasting, a condition well known to be associated with energy conservation, resulted in the upregulation of UCP3 mRNA expression [23], and prolonged cold exposure decreased UCP3 expression but increased energy metabolism [24]. These results suggested that UCP3 might be related, and even contribute to energy metabolism, but that the physiological function of UCP3 is not the regulation of energy expenditure. Therefore, these conflicting data have urged researchers to search for alternative functions of UCP3.

\section{A role for UCP3 in the production of reactive oxygen species?}

An alternative function has been proposed for UCP3 as a regulator of the production of reactive oxygen species 
(ROS). Early work from Skulachev [25] suggested that mitochondria possessed mild uncoupling, thereby preventing large increases in proton gradient when ADP was not available (state 4 respiration). A major part of ROS is produced by the respiratory chain, and ROS production increases with increasing proton gradient [25]. By lowering the proton gradient, UCP3 could decrease the production of ROS, and thereby prevent damage to molecules such as lipids, proteins and DNA. Evidence for this putative role of UCP3 came from the finding that mitochondria isolated from mice lacking UCP3 have an increased ROS production [ $9^{\bullet} \cdot$. A role for UCP 3 in the regulation of ROS production also fits with the finding that UCP3 expression decreases with aging, because aging has been associated with increased ROS production [26 ${ }^{\bullet}$. Furthermore, UCP3 was rapidly upregulated after acute exercise [27], and it could be suggested that such an upregulation serves to prevent the well-known increase of ROS production during exercise. However, we recently showed that the upregulation of UCP3 after acute exercise could be prevented by the administration of glucose drinks during exercise, thereby lowering plasma fatty acid levels and fat oxidation, suggesting that the increase in plasma free fatty acid levels or fat oxidation was responsible for the exercise-induced increase in UCP3 [28*0]. This would suggest that either UCP3 does not play a role in the defence of ROS formation, or that the exercise-induced formation of ROS is increased in the fasted state. Indeed, high intracellular levels of fatty acids result in increased ROS formation, and it might thus be/that UCP3 specifically plays a role in preventing fatty acidinduced ROS formation [29]. However, the fact that the expression of UCP3 is restricted to skeletal muscle, whereas ROS are produced in the mitochondria of all tissues, makes UCP3 (unlike UCP2) a less likely candidate to be involved in the prevention of the production of ROS.

\section{A role for UCP3 in type 2 diabetes mellitus?}

The use of chemical uncouplers of ATP production in muscle cells has revealed that mitochondrial uncoupling leads to increased glucose uptake, and to the synthesis of GLUT4 and GLUT4 translocation [30]. Recently, Huppertz et al. [31 •*] showed that the overexpression of UCP3 in L6 myotubes also increased glucose uptake, through an increased recruitment of GLUT4 to the cell surface. Furthermore, mice overexpressing UCP3 were characterized by lower plasma glucose and insulin levels and an improved glucose clearance rate [10 ${ }^{\bullet \bullet}$. It has also been shown that UCP3 is upregulated by insulin in vitro [32॰]. These data would suggest that UCP3 could be involved in the regulation of glucose metabolism and the development of type 2 diabetes mellitus. Evidence for the latter comes from several findings: we found a polymorphism in the promotor of UCP3, a $\mathrm{C}$ to $\mathrm{T}$ substitution 55 base pairs upstream of the transcriptionstarting site. Carriers of the $\mathrm{T}$ allele were characterized by increased mRNA expression [33], and recently the T allele was associated with a lowered risk of developing type 2 diabetes mellitus [34]. Furthermore, we recently found that UCP3 protein levels are twofold lower in type 2 diabetic individuals compared with controls [35 $\left.{ }^{\circ}\right]$. Finally, using immunofluoresence, we showed that UCP3 protein has the highest expression in type $2 \mathrm{~b}$ muscle fibres, which are highly glycolytic [36 $\left.{ }^{\bullet}\right]$.

If UCP3 is indeed involved in the regulation of glucose metabolism, the upregulation of UCP3 would be beneficial for the treatment of type 2 diabetes mellitus. One mechanism by which UCP3 could exert such beneficial effects is via the enzyme adenosine monophosphate (AMP)-activated protein kinase (AMPK), an enzyme responsible for the phosphorylation of key enzymes that control metabolic flux, including glucose uptake (via GLUT4 translocation) [37 ${ }^{\bullet}$ ]. This kinase can allosterically be activated by AMP. Phosphorylation of AMPK by an upstream kinase, AMPK-kinase (which is also allosterically activated by AMP), will also result in activation. Both AMPK and AMPK-kinase are inactivated by high concentrations of ATP, so that the AMP : ATP ratio is important in determining the activity status of AMPK. Therefore, decreases in the energy status of the cell, for example during muscle contraction, will lead to the activation of key enzymes involved in substrate metabolism, allowing for increased energy production. We hypothesize that high levels of UCP3 might stimulate glucose uptake through AMPK activation. Uncoupling of mitochondria will diminish ATP production, and when ATP production falls the cell has an alternative route to synthesize ATP: two molecules of ADP can be used to form one molecule of ATP, under the formation of one molecule of AMP. Therefore, high UCP3 could lead to an increased AMP concentration and activation of AMPK, thereby promoting glucose uptake and substrate metabolism. Whether the upregulation of UCP3 indeed activates AMP-kinase should be the topic of future research.

\section{UCP3 as a transporter of fatty acids?}

Apart from a role in glucose metabolism, UCP3 has also been suggested to play a role in the metabolism of fatty acids [38 $8^{\circ}$. Genetic studies [39] revealed that carriers of a mutation in exon- 6 of the UCP3 gene, resulting in the transcription of only the short isoform of UCP3, are characterized by a $50 \%$ reduction in basal fatty acid oxidation. Similarly, mice lacking UCP3 were characterized by a reduced capacity to oxidize fatty acids, especially in the fed state [40 ${ }^{\circ}$. It is generally found that UCP3 expression is upregulated in situations in which plasma free fatty acid levels or fat oxidation is high, such as fasting [23], acute exercise [28*0] and a 
high-fat diet $\left[41^{\circ}\right]$. The upregulation of UCP3 in cancer cachexia could be prevented by the administration of the hypolipidaemic agent nicotinic acid, indicating that the increased UCP3 expression was more closely related to increased free fatty acid levels than to increased energy expenditure [42 ${ }^{\circ}$. On the other hand, UCP3 expression was low or downregulated in situations in which fat oxidative capacity was high or improved, such as after endurance training [16], after weight reduction $\left[1^{\circ}\right]$ and in type 1 (slow-oxidative) muscle fibres [36 $6^{\circ}$. In situations in which fatty acid delivery to the mitochondria exceeds the capacity to oxidize these fatty acids, accumulation of non-esterified fatty acids in the cytoplasm is likely to occur. In such situations, some nonesterified fatty acids could partition into the mitochondrial phospolipid bilayer and flip-flop to the other side of the inner mitochondrial membrane, where they could be released into the mitochondrial matrix. Because of $\mathrm{pH}$ differences, these non-esterified fatty acids would then be deprotonated, leaving fatty acid anions. Because fatty acid anions can neither be metabolized inside the matrix, nor can they cross the inner mitochondrial membrane, accumulation of non-esterified fatty acid anions inside the matrix might occur. We recently postulated the hypothesis that UCP3 might be involved in the outward translocation of fatty acid anions from the mitochondrial matrix, in situations in which fatty acid delivery to the mitochondria exceeds oxidation [43 ${ }^{\circ}$. At present, studies are underway to test this hypothesis. A similar hypothesis was postulated by Himms-Hăgen and Harper [44 ${ }^{\circ}$, According to their hypothesis, UCP3 also- serves to export fatty acid anions from the mitochondrial matrix; however, they suggested that the fatty acid anions inside the matrix are delivered by the hydrolysis of acylcoenzyme A by mitochondrial thioesterases. Support for their hypothesis was provided by the notion that mice overexpressing UCP3 also have an increased expression of mitochondrial thioesterases $\left[45^{\circ}\right]$, and that the thiazolidinedione-induced changes in UCP3 correlated with the changes in mitochondrial thioesterases [46 $\left.{ }^{\circ}\right]$. However, the upregulation of UCP3 in myotubes after treatment with etomoxir [47 ${ }^{\circ}$, which blocks CPT1 and therefore inhibits $\beta$-oxidation and fat oxidation, seems to be less compatible with the latter hypothesis. Certainly both hypotheses need further examination.

\section{Conclusion}

Five years after the discovery of the UCP1 homologue, UCP3, its physiological function is still unsolved. Several findings indicate that UCP3 might be related to energy metabolism; however, based on the upregulation of UCP3 in the fasting state and the lack of phenotype in UCP3 knockout mice, it is clear that the primary function of UCP3 is not to regulate energy metabolism. Alternative functions for UCP3 have been postulated, with a role for UCP3 in the regulation of ROS production, glucose metabolism or fatty acid transport. At present, there is evidence both for and against all these putative functions, and many more studies are needed to test them. Studies manipulating UCP3 within the physiological range are awaited to resolve some of the current paradoxes.

Even though the primary function of UCP3 is not the regulation of energy metabolism, UCP3 might still influence energy expenditure as a secondary effect of its physiological function. Therefore, once the physiological function of UCP3 is revealed it might still be an interesting target for the treatment and prevention of obesity and type 2 diabetes.

\section{Acknowledgements}

Dr Schrauwen was supported by a grant from the Netherlands Organization for Scientific Research (NWO).

\section{References and recommended reading}

Papers of particular interest, published within the annual period of review, have been highlighted as:

- of special interest

- of outstanding interest

1 Mitchell P. Chemiosmotic coupling in oxidative and photosynthetic phosphorylation. Biol Rev Camb Philos Soc 1966; 41:445-502.

2 Rolfe DFS, Brown GC. Cellular energy utilization and molecular origin of standard metabolic rate in mammals. Physiol Rev 1997; 77:731-758.

3 Nicholls D, Bernson V, Heaton G. The identification of the component in the inner membrane responsible for regulating energy dissipation. In: Effectors of thermogenesis. Girardier L, Seydoux J (editors). Basel: Birkhauser Verlag; 1978. pp. 89-93.

4 Klingenberg $M$, Echtay $K S$, Bienengraeber $M$, et al. Structure-function relationship in UCP1. Int J Obes Relat Metab Disord 1999; 23 (Suppl. 6):S24-S29.

5 Jezek $\mathrm{P}$, Engstová $\mathrm{H}$, Zácková $\mathrm{M}$, et al. Fatty acid cycling mechanism and mitochondrial uncoupling proteins. Biochim Biophys Acta 1998; 1365:319327.

6 Fleury C, Neverova M, Collins S, et al. Uncoupling protein-2: a novel gene linked to obesity and hyperinsulinemia. Nat Genet 1997; 15:269-273.

7 Boss O, Samec S, Paoloni-Giacobino A, et al. Uncoupling protein-3: a new member of the mitochondrial carrier family with tissue-specific expression. FEBS Lett 1997; 408:39-42.

8 Gong D-W, He Y, Karas M, Reitman M. Uncoupling protein-3 is a mediator of thermogenesis regulated by thyroid hormone, $\beta 3$-adrenergic agonists, and leptin. J Biol Chem 1997; 272:24129-24132.

9 Vidal-Puig AJ, Grujic D, Zhang CY, et al. Energy metabolism in uncoupling -. protein 3 gene knockout mice. J Biol Chem 2000; 275:16258-16266.

A report on the creation of UCP3 knockout mice. The mitochondria of these mice indeed showed improved coupling, but the major finding is that these mice have no apparent phenotype, i.e. are not obese.

10 Clapham JC, Arch JR, Chapman $\mathrm{H}$, et al. Mice overexpressing human -. uncoupling protein-3 in skeletal muscle are hyperphagic and lean. Nature 2000; 406:415-418.

Mice overexpressing human UCP3 were created. These mice are hyperphagic but lean, indicating an increased metabolic rate. UCP3 overexpression improved glucose handling, suggesting a role for UCP3 in glucose metabolism.

11 Cline GW, Vidal-Puig AJ, Dufour S, et al. In vivo effects of uncoupling protein-3 - gene disruption on mitochondrial energy metabolism. J Biol Chem 2001; 276:20240-20244.

Further characterization of the UCP3 knockout mice previously described in Ref. $\left[9^{\bullet} \cdot\right.$. In-vivo uncoupling was determined by measuring the rate of ATP synthesis and TCA cycle flux using NMR. The results show the first evidence for in-vivo uncoupling activity of UCP3 in skeletal muscle. 
12 Bouchard C, Pérusse L, Chagnon YC, et al. Linkage between markers in the vicinity of the uncoupling protein 2 gene and resting metabolic rate in humans. Hum Mol Genet 1997; 6:1887-1889.

13 Dalgaard LT, Pedersen O. Uncoupling proteins: functional characteristics and role in the pathogenesis of obesity and type II diabetes. Diabetologia $2001 ; 44: 946-965$.

14 Ricquier D, Bouillaud F. The uncoupling protein homologues: UCP1, UCP2, -. UCP3, StUCP and AtUCP. Biochem J 2000; 345:161-179.

An excellent and extensive review of the current state of knowledge of mitochondrial uncoupling proteins.

15 Schrauwen P, Xia J, Bogardus C, et al. Skeletal muscle UCP3 expression is a determinant of energy expenditure in Pima Indians. Diabetes 1999; 48:146149.

16 Schrauwen P, Troost FJ, Xia J, et al. Skeletal muscle UCP2 and UCP3 expression in trained and untrained male subjects. Int J Obes Relat Metab Disord 1999; 23:966-972.

17 Schrauwen P, Schaart G, Saris WHM, et al. The effect of weight reduction on - skeletal muscle UCP2 and UCP3 mRNA expression and UCP3 protein content in type II diabetic subjects. Diabetologia 2000; 43:1408-1416.

The UCP3 protein content was reduced after weight reduction in type 2 diabetic subjects. The degree of reduction was related to the degree of weight loss, with the subjects that lost most weight having the least change in UCP3 protein. The results suggest that high levels of UCP3 protein might facilitate weight loss.

18 Simonyan RA, Jimenez M, Ceddia RB, et al. Cold-induced changes in the energy coupling and the UCP3 level in rodent skeletal muscles. Biochim Biophys Acta 2001; 1505:271-279.

19 Sanchís D, Busquets S, Alvarez B, et al. Skeletal muscle UCP2 and UCP3 gene expression in a rat cancer cachexia model. FEBS Lett 1998; 436:415418.

20 de Lange $\mathrm{P}$, Lanni $\mathrm{A}$, Beneduce $\mathrm{L}$, et al. Uncoupling protein-3 is a molecular - determinant for the regulation of resting metabolic rate by thyroid hormone. Endocrinology 2001; 142:3414-3420.

The time course of resting metabolic rate and UCP3 protein content in response to triiodothyronine injection in rats showed striking similarities, with highest resting metabolic rate and UCP3 protein $65 \mathrm{~h}$ after injection. The study suggests that UCP3 might be involved in thyroid-induced thermogenesis.

21 Lebon V, Dufour S, Petersen KF, et al. Effect of triiodothyronine on - mitochondrial energy coupling in human skeletal muscle. J Clin Invest 2001; 108:733-737

Human subjects were treated for 3 days with triiodothyronine hormone, and mitochondrial coupling was measured using NMR. Triiodothyronine treatment improved in-vivo mitochondrial coupling in human skeletal muscle, possibly as a result of increased UCP3 (not measured).

22 Gong DW, Monemdjou S, Gavrilova O, et al. Lack of obesity and normal - response to fasting and thyroid hormone in mice lacking uncoupling protein-3. J Biol Chem 2000; 275:16251-16257.

Detailed phenotypical characterization of UCP3 knockout mice. The results indicate that UCP3 is responsible for a great part of the proton leak in muscle, but that the lack of UCP3 does not affect body weight, body temperature or oxidative capacity in response to fasting and thyroid hormone.

23 Millet $L$, Vidal $H$, Andreelli $F$, et al. Increased uncoupling protein-2 and -3 mRNA expression during fasting in obese and lean humans. J Clin Invest 1997; 100:2665-2670.

24 Schrauwen P, Westerterp-Plantenga MS, Kornips E, et al. The effect of mild cold exposure on UCP3 mRNA expression and UCP3 protein content in humans. Int J Obes Relat Metab Disord 2002; in press.

25 Skulachev VP. Uncoupling: new approaches to an old problem of bioenergetics. Biochim Biophys Acta 1998; 1363:100-124.

26 Kerner J, Turkaly PJ, Minkler PE, Hoppel CL. Aging skeletal muscle mitochondria in the rat: decreased uncoupling protein-3 content. Am J Physiol Endocrinol Metab 2001; 281:E1054-E1062.

Aging decreases UCP3 content and state 4 respiration in rats.

27 Pilegaard H, Ordway GA, Saltin B, Neufer PD. Transcriptional regulation of gene expression in human skeletal muscle during recovery from exercise. Am J Physiol Endocrinol Metab 2000; 279:E806-E814.

28 Schrauwen P, Hesselink MKC, Vaartjes I, et al. The effect of acute exercise on - uncoupling protein 3 is a fat metabolism mediated effect. Am J Physiol Endocrinol Metab 2002; 282:E11-E17.

Acute exercise increased UCP3 mRNA expression 4 hours post-exercise in untrained human subjects. The increase was prevented by administration of glucose drinks, suggesting that the exercise-induced increase in UCP3 is related to changes in free fatty acids and/or fat oxidation.
29 Maziere C, Conte MA, Degonville J, et al. Cellular enrichment with polyunsaturated fatty acids induces an oxidative stress and activates the transcription factors AP1 and NFkappaB. Biochem Biophys Res Commun 1999; 265:116-122.

30 Bashan N, Burdett E, Guma A, et al. Mechanisms of adaptation of glucose transporters to changes in the oxidative chain of muscle and fat cells. Am J Physiol 1993; 264:C430-C440.

31 Huppertz C, Fischer BM, Kim YB, et al. Uncoupling protein 3 (UCP3) stimulates

- glucose uptake in muscle cells through a phosphoinositide 3-kinase-dependent mechanism. J Biol Chem 2001; 276:12520-12529.

The overexpression of human UCP3 in L6 myotubes increases glucose uptake. The effect could be prevented by wortmannin, suggesting that UCP3 increases glucose uptake via the phosphatidylinositol 3 kinase-dependent pathway.

32 Pedersen SB, Lund S, Buhl ES, Richelsen B. Insulin and contraction directly - stimulate UCP2 and UCP3 mRNA expression in rat skeletal muscle in vitro. Biochem Biophys Res Commun 2001; 283:19-25.

The first report showing that insulin is able to induce UCP3 expression rapidly in rat skeletal muscle in vitro.

33 Schrauwen $\mathrm{P}$, Xia J, Walder $\mathrm{K}$, et al. A novel polymorphism in the proximal UCP3 promoter region: effect on skeletal muscle UCP3 mRNA expression and obesity in male non-diabetic Pima Indians. Int J Obes Relat Metab Disord 1999; 23:1242-1245.

34 Meirhaeghe A, Amouyel P, Helbecque N, et al. An uncoupling protein 3 gene polymorphism associated with a lower risk of developing type II diabetes and with atherogenic lipid profile in a French cohort. Diabetologia 2000; 43:14241428.

An association study, examining a $\mathrm{C}$ to $\mathrm{T}$ substitution in the promotor of UCP3. The T-allele frequency, previously associated with increased UCP3 mRNA expression, was lower in diabetic subjects.

35 Schrauwen $\mathrm{P}$, Hesselink MKC, Blaak EE, et al. Uncoupling protein 3 content is decreased in skeletal muscle of patients with type 2 diabetes mellitus. Diabetes 2001; 50:2870-2873

UCP3 protein content was twofold lower in patients with type 2 diabetes compared with controls, independent of body mass index.

36 Hesselink MKC, Keizer HA, Borghouts LB, et al. Protein expression of UCP3

- differs between human type 1, type $2 a$ and type $2 b$ fibers. FASEB J 2001 15:1071-1073

Immunofluoresence was combined with conventional fibre typing to study fibre type and UCP3 expression in human vastus lateralis muscle concurrently. UCP3 protein expression was most abundant in type $2 b$ fibres, less in type $2 a$ fibres, and only moderately expressed in type 1 fibres.

37 Winder WW. Energy-sensing and signaling by AMP-activated protein kinase in -. skeletal muscle. J Appl Physiol 2001; 91:1017-1028.

An excellent review of the suggested mechanisms and putative functions of AMPK.

38 Dulloo AG, Samec S. Uncoupling proteins: their roles in adaptive thermogen- $\quad$ esis and substrate metabolism reconsidered. Br J Nutr 2001; 86:123-139.

A recent review on the putative roles of UCP2 and UCP3. It was concluded that UCP 3 is involved in the flux of lipid substrates across the mitochondria.

39 Argyropoulos G, Brown AM, Willi SM, et al. Effects of mutations in the human uncoupling protein 3 gene on the respiratory quotient and fat oxidation in severe obesity and type 2 diabetes. J Clin Invest 1998; 102:1345-1351.

40 Bezaire V, Hofmann W, Kramer JK, et al. Effects of fasting on muscle - mitochondrial energetics and fatty acid metabolism in Ucp3 $(-/-)$ and wildtype mice. Am J Physiol Endocrinol Metab 2001; 281:E975-E982.

UCP3 knockout mice showed reduced resting respiratory quotient, implying a role for UCP3 in fatty acid metabolism. State 4 respiration was not altered in UCP3 knockout mice.

41 Schrauwen $\mathrm{P}$, Hoppeler $\mathrm{H}$, Billeter $\mathrm{R}$, et al. Fiber type dependent upregulation - of human skeletal muscle UCP2 and UCP3 mRNA expression by high-fat diet. Int J Obes Relat Metab Disord 2001; 25:449-456.

In human subjects, 4 weeks of high-fat diet increased UCP3 mRNA expression. The increase was most pronounced in subjects with a high percentage of type lla muscle fibres.

42 Busquets S, Carbo N, Almendro V, et al. Hyperlipemia: a role in regulating - UCP3 gene expression in skeletal muscle during cancer cachexia? FEBS Lett 2001; 505:255-258.

This study indicates that the increased expression of UCP3 in the cancer cachexia state in rats is related to high plasma free fatty acid levels. The administration of nicotonic acid, to lower plasma free fatty acid levels, reduced UCP3 expression. 
43 Schrauwen $\mathrm{P}$, Saris $\mathrm{WH}$, Hesselink MK. An alternative function for human - uncoupling protein 3: protection of mitochondria against accumulation of nonesterified fatty acids inside the mitochondrial matrix. FASEB J 2001; 15:2497-2502.

A critical review and analysis of the available human UCP3 data. On the basis of the present data it is suggested that UCP3 might act as a transporter of fatty acid anions out of the mitochondrial matrix, thereby protecting mitochondria against accumulations of fatty acids.

44 Himms-Hagen J, Harper ME. Physiological role of UCP3 may be export of fatty - acids from mitochondria when fatty acid oxidation predominates: an hypothesis. Exp Biol Med (Maywood) 2001; 226:78-84.

A hypothesis on the putative function of UCP3 as a transporter of fatty acid anions out of the mitochondrial matrix. It proposes that excess acyl-coenzyme $A$ within the mitochondria is hydrolysed by a mitochondrial acyl-coenzyme A thioesterase, yielding fatty acid anion and the sulfhydryl group of coenzyme $A$.

45 Moore GB, Himms-Hagen J, Harper ME, Clapham JC. Overexpression of UCP-

- 3 in skeletal muscle of mice results in increased expression of mitochondrial thioesterase mRNA. Biochem Biophys Res Commun 2001; 283:785-790.

This study provides evidence for the hypothesis in Ref [44 ${ }^{\circ}$. Mice overexpressing UCP3 have increased thioesterase mRNA expression, to make fatty acid anions available for UCP3.
46 Clapham JC, Coulthard VH, Moore GB. Concordant mRNA expression of

- UCP-3, but not UCP-2, with mitochondrial thioesterase-1 in brown adipose tissue and skeletal muscle in $\mathrm{db} / \mathrm{db}$ diabetic mice. Biochem Biophys Res Commun 2001; 287:1058-1062.

See Ref. [44 ${ }^{\bullet}$. Thioesterase expression was related to UCP3 expression.

47 Cabrero A, Alegret $M$, Sanchez $R$, et al. Uncoupling protein-3 mRNA up- regulation in $\mathrm{C} 2 \mathrm{C} 12$ myotubes after etomoxir treatment. Biochim Biophys Acta 2001; 1532:195-202.

Etomoxir, a blocker of carnitine palmitoyl transferase 1, which thereby prevented the entry of fatty acids into the mitochondria, resulted in increased UCP3

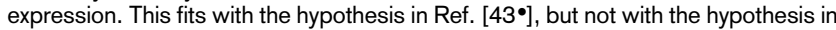
Ref. [44].
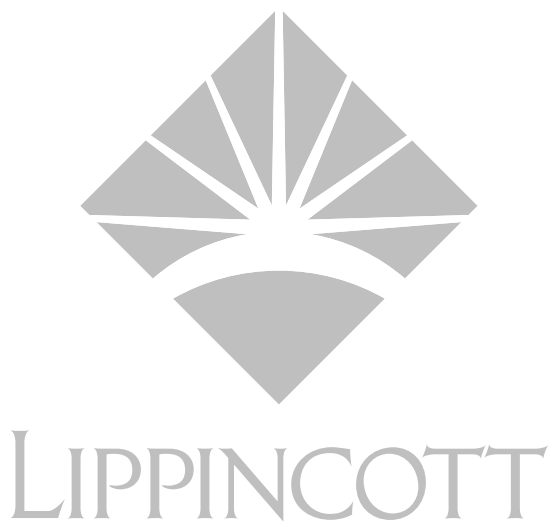